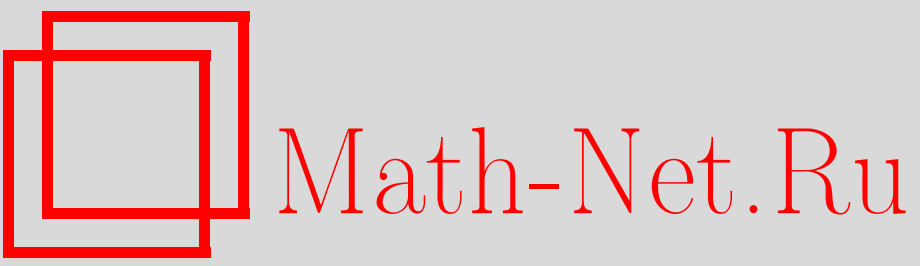

А. С. Джумадильдаев, Ш. Ш. Ибраев, Определяющие соотношения нильпотентных подалгебр модулярных классических алгебр Ли, УМН, 1998, том 53, выпуск 5, 233-234

DOI: https://doi.org/10.4213/rm81

Использование Общероссийского математического портала Math-Net.Ru подразумевает, что вы прочитали и согласны с пользовательским соглашением

http://www. mathnet.ru/rus/agreement

Параметры загрузки:

IP: 3.85 .73 .92

26 апреля 2023 г., 12:45:46 


\title{
ОПРЕДЕЛЯЮЩИЕ СООТНОШЕНИЯ НИЛЬПОТЕНТНЫХ ПОДАЛГЕБР МОДУЛЯРНЫХ КЛАССИЧЕСКИХ АЛГЕБР ЛИ
}

\author{
А. С. ДЖУМАДИЛЬДАЕВ, Ш.Ш. ИБРАЕВ
}

Пусть $\mathbf{a}=\left(a_{i, j}\right)$ - матрица Картана ранга $n, \Gamma(\mathbf{a}), \mathfrak{g}(\mathbf{a})$ - соответствующие система корней и алгебра Ли ([1], [2]), $k$ - основное поле характеристики $p \geqslant 0$. Базис в $\mathfrak{g}(\mathbf{a})(k=\mathbf{C})$ можно подобрать так, что структурные константы будут целыми. Простая алгебра Ли $\mathfrak{g}(\mathbf{a})$ порождается $3 n$ образующими и соотношениями Серра. Нас интересуют нильпотентная подалгебра, порожденная элементами положительных корней. В случае характеристики нуль эта подалгебра порождаются соотношениями вида ad $e_{i}^{1-a_{j, i}} e_{j}=0$. Поскольку структурные константы целые, мы можем рссматривать ее и над полями характеристики $p>0$. Обозначим полученную алгебру через $\mathfrak{n}^{+}(\mathbf{a})$. Итак, размерность $\mathfrak{n}^{+}(\mathbf{a})$ совпадает с количеством положительных корней $\Gamma^{+}(\mathbf{a})$.

Простые алгебры Ли $\mathfrak{g}(\mathbf{a})$ при редукции по модулю $p>0$ могут перестать быть простыми. Например, алгебры Ли типов $B_{n}, C_{n}, D_{n}, F_{4}, E_{7},-$ непростые при $p=2$. Алгебры Ли $D_{2 k+1}$ и $E_{7}$ $(p=2), E_{6},(p=3)$, содержат одномерные центры, $D_{2 k}$ имеет двумерный центр $A_{n p-1}$ имеет одномерньй центр, факторалгебры по которым простые. При $p=3,2$ алгебра Ли $G_{2}$ имеет идеал и факторалгебру изоморфиню $A_{2}$ и $A_{3}$. А также $C_{n}$ содержит идеал $D_{n}, B_{n}$ - идеал, факторалгебра по которому есть $D_{n}$, и $F_{4}$ содержит идеал $D_{4}$. С учетом перекрестных изоморфизмов и факторизации под простыми алгебрами Ли классических типов над полем $k$ характеристики $p>0$, будем понимать простые алгебры следующих типов: $A_{n}(n>1), B_{n}(n>1, p>2)$, $C_{n}(n>2, p>2), D_{n}(n>3), G_{2}(p>3), F_{4}(p>2), E_{6}, E_{7}, E_{8}$. Внизу используется запись $[x, y, z, t, \ldots]$ вместо $[\ldots[[[x, y], z], t] \ldots]$.

ТЕОрема. Пусть $\mathfrak{n}^{+}$- нильпотентная подалгебра простой классической алгебрь Ли, $p>0$. Если $p>3$, то $\mathfrak{n}^{+}$, как и в случае характеристики 0, порождается соотношениями Серра $\operatorname{ad} e_{i}^{1-a_{j, i}} e_{j}=0$. При $p=2,3$ определяющие соотношения алгебрь Ли $\mathfrak{n}^{+}$состоят из соотношении Серра и из дополнительных соотношении (список cм. ниже).

\section{Список дополнительных соотношении.}

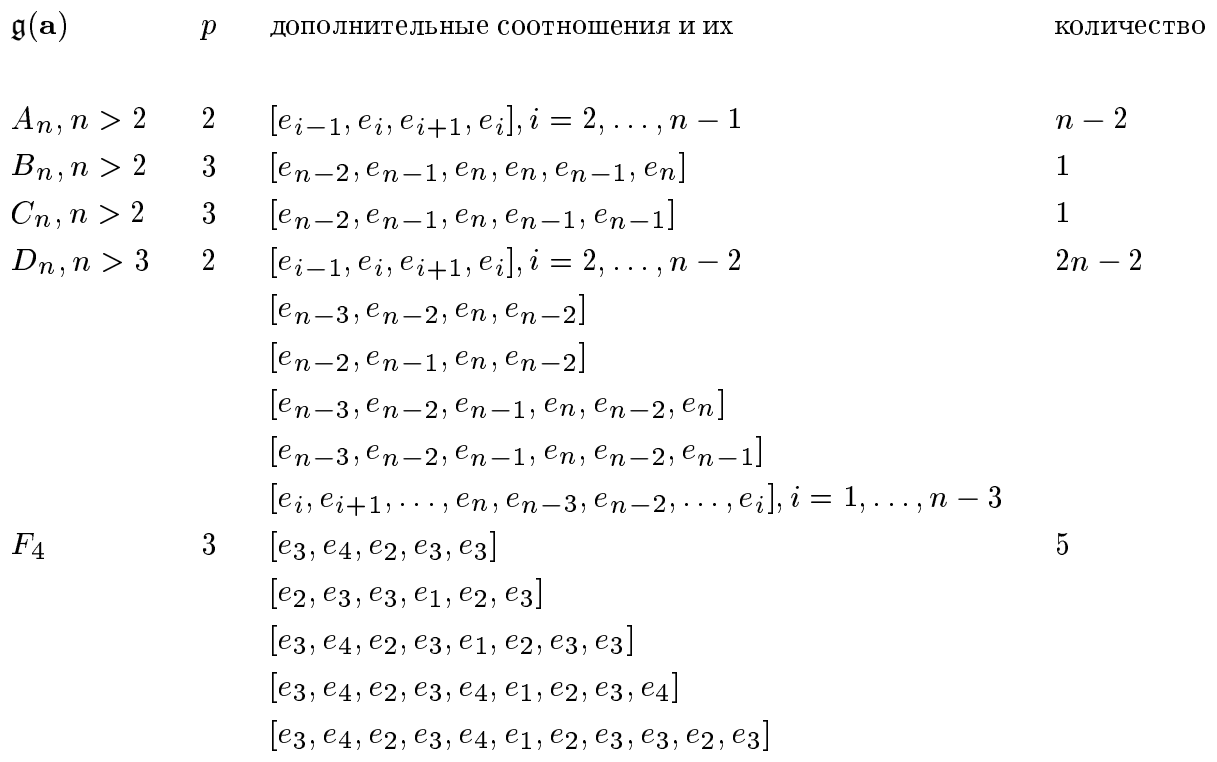




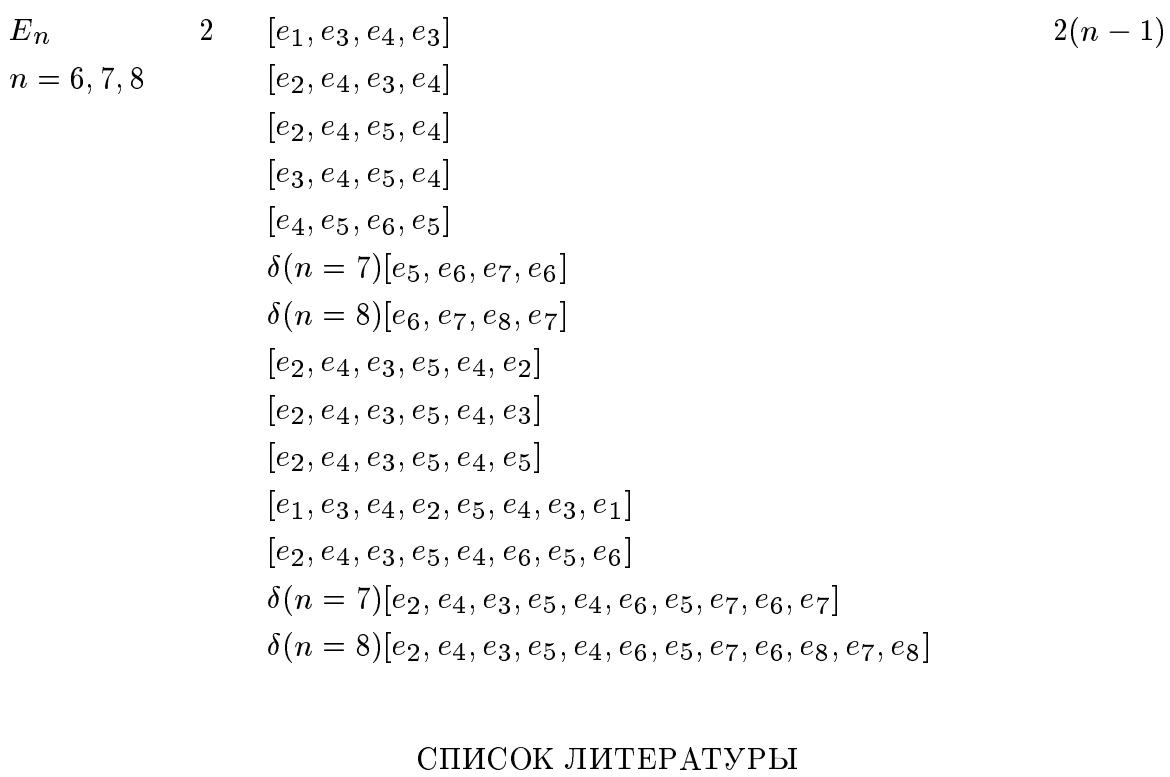

[1] Seligman G. B. Modular Lie Algebras. Berlin: Springer-Verlag, 1967. [2] Cepp ЖK. П. Группы Ли и алгебры Ли. М.: Мир, 1969. 